\title{
On the Uniqueness and Non-Commutative Nature of Coefficients of Variables and Interactions in Hierarchical Moderated Multiple Regression of Masked Survey Data
}

\author{
H. I. Okagbue
}

Department of Mathematical Sciences, Covenant University, Canaanland, Ota, Nigeria hilary.okagbue@covenantuniversity.edu.ng

M. O. Adamu

Department of Mathematics, University of Lagos, Akoka, Nigeria

S. A. lyase

Department of Mathematical Sciences, Covenant University, Canaanland, Ota, Nigeria

S. O. Edeki

Department of Mathematical Sciences, Covenant University, Canaanland, Ota, Nigeria

A. A. Opanuga

Department of Mathematical Sciences, Covenant University, Canaanland, Ota, Nigeria

P. O. Ugwoke

Department of Computer Science, University of Nigeria, Nsukka, Nigeria Digital Bridge Institute, International Centre for Communication Studies, Abuja, Nigeria

Doi:10.5901/mjss.2015.v6n4s3p408

\section{Abstract}

The paper introduces the concept of reverse moderation in order to investigate the uniqueness of the coefficients of independent variables and non-commutative nature of interactions in moderated multiple regression (MMR) in hierarchical order. The moderation effect is 0.01and the data used was masked to maintain the integrity of an ongoing research. The research concludes that moderation and its reverse yield different results indicating the uniqueness of the coefficients of the independent variables and the interactions are not commutative. Interactions are one-way. Each case is different as shown by the results of the 20 models used.

Keywords: Moderation, Reverse moderation, regression, uniqueness, commutative, hierarchical.

\section{Introduction}

A moderator interacts with the predictor variable in such a way as to have an impact on the level of the dependent variable (High, 2015), (Bobko and Russell, 1994). Saunders (1956) was one of the early researchers that strongly advocated for the use of moderation, which was further re-emphasized by Stone and Hollenbeck (1984). Also, according to Holmbeck (1997), a moderator variable is one that affects the relationship between two variables such that the nature of the impact of the predictor on the criterion varies according to the level or the value of the moderator. Moderation can be done using a two-level regression model (Yuan et al, 2013) while moderated multiple regression MMR is more powerful than sub grouped-based correlation coefficient (Stone-Romero and Anderson, 1994). Interaction effects was properly define by Aguinis (2002) and Aiken and West (1991) among many authors.

Zedeck (1997) identified major problems of moderator variables as operation and identification of moderator variables, Dunlap and Kemery (1987) and Shieh (2010) amongst others addressed the problems of multicollinearity. The futility of mean centering in reducing collinearity was highlighted by Echambadi and Hess (2007), however, using mean 
centering can reduce non-essential collinearity in moderation and regression (Dalal and Zickar, 2012). Aguinis and Gottfredson (2010) described in details the procedures for estimating and interpreting interaction effects using MMR. Arnold (1982) and Aguinis et al (2005) advocated for statistical tests for moderator variables. Interactions and moderator effects can at times be difficult to detect (McClelland and Judd, 1993) and there are advantages in reporting confidence intervals in MMR analysis (Shieh, 2010). See the works of (Bobko and Russell, 1994) and (Champoux and Peters, 1987) for the summary of MMR.

\section{Literature Review}

Several authors have done researches on the coefficients of variables and interactions in moderated multiple regression. Fisicaro and Tisak (1994) showed from their research that MMR technique is most suited for cases where the independent variables are fixed and warned that inappropriate use of MMR in cases where the independent variables are random. Baron and Kenny (1986) focused on the statistical interpretations of MMR, Evans (1985) addressed the issues of multicollinearity as it relates to coefficients of variables and interactions. Intercorrelation can also lead to false interpretation of coefficients of variables and interactions (Dunlap and Kemery, 1988). Schriesheim (1995) gave the detailed mathematics of moderation while some steps in interpretation of interactions was given by Bedeian and Mossholder (1994), Irwin and McClelland (2001). See (O'Connor, 2006), and (Jaccard et al, 1990) and (Russell and Bobko, 1992) for interactions of continuous variables. Aguinis et al (1996) recommended some methods of improving the estimation of moderating effects while Paunonen and Jackson (1988) recommended principal component regression as an alternative to moderated multiple regression. In other to improve the efficiency of MMR technique, Anderson et al (1996) recommended the use of small sample size Cortina (1993) recommended the use of square terms as covariates. Fairchild and MacKinnon (2009) wrote on a general model that has the capability of estimating both mediation and moderation effects simultaneously.

\section{Research Motivations and Methodology}

The rationale for the research is to study the effect of reverse moderation on moderated multiple regression (MMR). Moderation known from literature review is one-way and we are to investigate whether it can be two-way. Meaning that if replacing the moderation variables with the independent variables (predictors) can yield the same results. This can be confirmed by checking whether the coefficients of both the independent and moderation variables are unchanged after the reverse moderation and also to check whether the interactions are invariant after the operation(s). Uniqueness implies that the coefficients are different in each operations and commutativity imply that the interactions are variant after the reverse moderation. This research is an extension of earlier works of Landis and Dunlap (2000). However, the authors limited their work to one predictor and moderator but this research work extended the scope to more than one predictor and moderator as seen in the result section of this paper. This research is also an extension of the research of Champoux and Peters (1987) where they used simulation to show how a moderator variable affects the form of relationship between two other variables. But this research extended it to more than two variables.

Thirdly, this research is also an extension of the paper published by Zedeck et al (1971) where they used two moderators in comparison with the result of linear regression. This research extended the scope to one, two, three and four moderators. Lastly, the research methodology is in agreement with the recommendations of Morse et al (2012) that stated that item response theory are more robust to spurious interaction effects in moderation analysis. This is because the data used was a subset of a survey.

$$
\begin{aligned}
& y=b_{0}+b_{1} x+b_{2} z+b_{3}(x \times z)=b_{00}+b_{11} x+b_{22} z+b_{33}(z \times x) \\
& \text { Uniqueness implies that: } \\
& b_{0}=b_{00}, b_{1}=b_{11}, b_{2}=b_{22} \\
& \text { Commutativity implies that: } \\
& b_{3}=b_{33}
\end{aligned}
$$

The data was masked but not fictitious; it is a subset of a current research. Masking means that the details of the survey were hidden. 


\section{Results}

\subsection{Regression}

The dependent variable $=y$, the independent variables are $x_{1}$ to $x_{8}$. The results of the coefficients of variables of the regression are summarized in table 1.

Table 1. The coefficients of the variables of the regression analysis.

\begin{tabular}{|c|c|c|c|c|c|c|c|c|c|}
\hline Variables & Constant & $x_{1}$ & $x_{2}$ & $x_{3}$ & $x_{4}$ & $x_{5}$ & $x_{6}$ & $x_{7}$ & $x_{8}$ \\
\hline Coefficients & 1.499 & -0.012 & 0.066 & 0.108 & 0.036 & -0.032 & 0.173 & -0.051 & 0.123 \\
\hline
\end{tabular}

\subsection{Moderated Multiple Regression}

For moderation, the dependent variable $=y$, the independent variables are $x_{1}$ to $x_{4}$, while the moderating variables are $x_{5}$ to $x_{8}$. The moderating variables moderates between the dependent variable and the predictors. To examine the uniqueness and non-commutativity or otherwise of the coefficients and interactions, the moderated multiple regression is repeated several times with the moderating variables moderating in different styles on the independent variables. Lastly for each moderated regression, the reverse case in done, that is, the independent variables replaces the moderating variables and vice versa. All these are done to examine whether the two equations generated in each case are related.

\section{Case 1.}

$x_{5}$ is the moderating variable only.

Table 2a. The coefficients of variables for case 1.

\begin{tabular}{|c|c|c|c|c|c|c|c|c|c|}
\hline Variables & Constant & $x_{1}$ & $x_{2}$ & $x_{3}$ & $x_{4}$ & $x_{5}$ & $x_{6}$ & $x_{7}$ & $x_{8}$ \\
\hline Coefficients & 1.797 & -0.001 & 0.061 & 0.106 & 0.04 & -0.147 & 0.18 & -0.051 & 0.121 \\
\hline
\end{tabular}

Table $2 \mathrm{~b}$. The coefficients of interactions for case 1.

\begin{tabular}{|c|c|c|c|c|}
\hline Interactions & $x_{1} x_{5}$ & $x_{2} x_{5}$ & $x_{3} x_{5}$ & $x_{4} x_{5}$ \\
\hline Coefficients & 0.119 & -0.11 & 0.002 & 0.101 \\
\hline
\end{tabular}

\section{The Reverse of Case 1.}

Table 3a. The coefficients of variables for the reverse of case 1.

\begin{tabular}{|c|c|c|c|c|c|c|c|c|c|}
\hline Variables & Constant & $x_{1}$ & $x_{2}$ & $x_{3}$ & $x_{4}$ & $x_{5}$ & $x_{6}$ & $x_{7}$ & $x_{8}$ \\
\hline Coefficients & 1.797 & -0.081 & 0.022 & 0.104 & 0.079 & -0.022 & 0.18 & -0.051 & 0.121 \\
\hline
\end{tabular}

Table 3b. The coefficients of interactions for the reverse of case 1.

\begin{tabular}{|c|c|c|c|c|}
\hline Interactions & $x_{5} x_{1}$ & $x_{5} x_{2}$ & $x_{5} x_{3}$ & $x_{5} x_{4}$ \\
\hline Coefficients & 0.08 & -0.165 & 0.002 & 0.123 \\
\hline
\end{tabular}

\section{Case 2.}

$x_{6}$ is the moderating variable only.

Table 4a. The coefficients of variables for case 2.

\begin{tabular}{|c|c|c|c|c|c|c|c|c|c|}
\hline Variables & Constant & $x_{1}$ & $x_{2}$ & $x_{3}$ & $x_{4}$ & $x_{5}$ & $x_{6}$ & $x_{7}$ & $x_{8}$ \\
\hline Coefficients & 1.557 & -0.011 & 0.063 & 0.11 & 0.036 & -0.036 & 0.151 & -0.052 & 0.124 \\
\hline
\end{tabular}


Table 4b. The coefficients of interactions for case 2.

\begin{tabular}{|c|c|c|c|c|}
\hline Interactions & $x_{1} x_{6}$ & $x_{2} x_{6}$ & $x_{3} x_{6}$ & $x_{4} x_{6}$ \\
\hline Coefficients & -0.003 & 0.007 & -0.035 & 0.054 \\
\hline
\end{tabular}

\section{The Reverse of Case 2.}

Table 5a. The coefficients of variables for the reverse of case 2 .

\begin{tabular}{|c|c|c|c|c|c|c|c|c|c|}
\hline Variables & Constant & $x_{1}$ & $x_{2}$ & $x_{3}$ & $x_{4}$ & $x_{5}$ & $x_{6}$ & $x_{7}$ & $x_{8}$ \\
\hline Coefficients & 1.557 & -0.009 & 0.056 & 0.148 & -0.009 & -0.031 & 0.169 & -0.052 & 0.124 \\
\hline
\end{tabular}

Table $5 \mathrm{~b}$. The coefficients of interactions for the reverse of case 2 .

\begin{tabular}{|c|c|c|c|c|}
\hline Interactions & $x_{6} x_{1}$ & $x_{6} x_{2}$ & $x_{6} x_{3}$ & $x_{6} x_{4}$ \\
\hline Coefficients & -0.002 & 0.009 & -0.042 & 0.042 \\
\hline
\end{tabular}

\section{Case 3.}

$x_{7}$ is the moderating variable only.

Table 6a. The coefficients of variables for case 3.

\begin{tabular}{|c|c|c|c|c|c|c|c|c|c|}
\hline Variables & Constant & $x_{1}$ & $x_{2}$ & $x_{3}$ & $x_{4}$ & $x_{5}$ & $x_{6}$ & $x_{7}$ & $x_{8}$ \\
\hline Coefficients & 1.94 & 0.003 & 0.063 & 0.107 & 0.038 & -0.031 & 0.172 & -0.218 & 0.124 \\
\hline
\end{tabular}

Table $6 \mathrm{~b}$. The coefficients of interactions for case 3.

\begin{tabular}{|c|c|c|c|c|}
\hline Interactions & $x_{1} x_{7}$ & $x_{2} x_{7}$ & $x_{3} x_{7}$ & $x_{4} x_{7}$ \\
\hline Coefficients & 0.205 & -0.022 & 0.003 & -0.019 \\
\hline
\end{tabular}

\section{The Reverse of Case 3.}

Table 7a. The coefficients of variables for the reverse of case 3.

\begin{tabular}{|c|c|c|c|c|c|c|c|c|c|}
\hline Variables & Constant & $x_{1}$ & $x_{2}$ & $x_{3}$ & $x_{4}$ & $x_{5}$ & $x_{6}$ & $x_{7}$ & $x_{8}$ \\
\hline Coefficients & 1.94 & -0.127 & 0.093 & 0.103 & 0.058 & -0.031 & 0.172 & -0.051 & 0.124 \\
\hline
\end{tabular}

Table $7 \mathrm{~b}$. The coefficients of interactions for the reverse of case 3

\begin{tabular}{|c|c|c|c|c|}
\hline Interactions & $x_{7} x_{1}$ & $x_{7} x_{2}$ & $x_{7} x_{3}$ & $x_{7} x_{4}$ \\
\hline Coefficients & 0.124 & -0.032 & 0.004 & -0.022 \\
\hline
\end{tabular}

\section{Case 4}

$x_{8}$ is the moderating variable only.

Table 8a. The coefficients of variables for case 4.

\begin{tabular}{|c|c|c|c|c|c|c|c|c|c|}
\hline Variables & Constant & $x_{1}$ & $x_{2}$ & $x_{3}$ & $x_{4}$ & $x_{5}$ & $x_{6}$ & $x_{7}$ & $x_{8}$ \\
\hline Coefficients & 1.548 & -0.01 & 0.063 & 0.11 & 0.036 & -0.029 & 0.177 & -0.051 & 0.078 \\
\hline
\end{tabular}


Table 8b. The coefficients of interactions for case 4.

\begin{tabular}{|c|c|c|c|c|}
\hline Interactions & $x_{1} x_{8}$ & $x_{2} x_{8}$ & $x_{3} x_{8}$ & $x_{4} x_{8}$ \\
\hline Coefficients & -0.016 & 0.171 & 0.014 & -0.111 \\
\hline
\end{tabular}

\section{The Reverse of Case 4}

Table 9a. The coefficients of variables for the reverse of case 4 .

\begin{tabular}{|c|c|c|c|c|c|c|c|c|c|}
\hline Variables & Constant & $x_{1}$ & $x_{2}$ & $x_{3}$ & $x_{4}$ & $x_{5}$ & $x_{6}$ & $x_{7}$ & $x_{8}$ \\
\hline Coefficients & 1.548 & -0.003 & -0.078 & 0.10 & 0.11 & -0.029 & 0.177 & -0.051 & 0.111 \\
\hline
\end{tabular}

Table $9 b$. The coefficients of interactions for the reverse of case 4 .

\begin{tabular}{|c|c|c|c|c|}
\hline Interactions & $x_{8} x_{1}$ & $x_{8} x_{2}$ & $x_{8} x_{3}$ & $x_{8} x_{4}$ \\
\hline Coefficients & -0.007 & 0.165 & 0.012 & -0.085 \\
\hline
\end{tabular}

\section{Case 5}

$x_{5}$ is the moderating variable for $x_{1}, x_{6}$ is the moderating variable for $x_{2}, x_{7}$ is the moderating variable for $x_{3}, x_{8}$ is the moderating variable for $x_{4}$.

Table 10a. The coefficients of variables for case 5.

\begin{tabular}{|c|c|c|c|c|c|c|c|c|c|}
\hline Variables & Constant & $x_{1}$ & $x_{2}$ & $x_{3}$ & $x_{4}$ & $x_{5}$ & $x_{6}$ & $x_{7}$ & $x_{8}$ \\
\hline Coefficients & 1.787 & -0.002 & 0.064 & 0.109 & 0.039 & -0.22 & 0.189 & -0.048 & 0.24 \\
\hline
\end{tabular}

Table 10b. The coefficients of interactions for case 5.

\begin{tabular}{|c|c|c|c|c|}
\hline Interactions & $x_{1} x_{5}$ & $x_{2} x_{6}$ & $x_{3} x_{7}$ & $x_{4} x_{8}$ \\
\hline Coefficients & 0.192 & -0.18 & 0.001 & -0.126 \\
\hline
\end{tabular}

\section{The Reverse of Case 5}

Table 11a. The coefficients of variables for the reverse of case 5.

\begin{tabular}{|c|c|c|c|c|c|c|c|c|c|}
\hline Variables & Constant & $x_{1}$ & $x_{2}$ & $x_{3}$ & $x_{4}$ & $x_{5}$ & $x_{6}$ & $x_{7}$ & $x_{8}$ \\
\hline Coefficients & 1.787 & -0.135 & 0.085 & 0.108 & 0.123 & -0.03 & 0.173 & -0.048 & 0.124 \\
\hline
\end{tabular}

Table 11b. The coefficients of interactions for the reverse of case 5 .

\begin{tabular}{|c|c|c|c|c|}
\hline Interactions & $x_{5} x_{1}$ & $x_{6} x_{2}$ & $x_{7} x_{3}$ & $x_{8} x_{4}$ \\
\hline Coefficients & 0.129 & -0.023 & 0.001 & -0.096 \\
\hline
\end{tabular}

\section{Case 6}

$x_{6}$ is the moderating variable for $x_{1}, x_{5}$ is the moderating variable for $x_{2}, x_{8}$ is the moderating variable for $x_{3}, x_{7}$ is the moderating variable for $x_{4}$.

Table 12a. The coefficients of variables for case 6 .

\begin{tabular}{|c|c|c|c|c|c|c|c|c|c|}
\hline Variables & Constant & $x_{1}$ & $x_{2}$ & $x_{3}$ & $x_{4}$ & $x_{5}$ & $x_{6}$ & $x_{7}$ & $x_{8}$ \\
\hline Coefficients & 1.461 & -0.10 & 0.063 & 0.105 & 0.037 & 0.075 & 0.117 & -0.063 & 0.048 \\
\hline
\end{tabular}


Table 12b. The coefficients of interactions for case 6 .

\begin{tabular}{|c|c|c|c|c|}
\hline Interactions & $x_{1} x_{6}$ & $x_{2} x_{5}$ & $x_{3} x_{8}$ & $x_{4} x_{7}$ \\
\hline Coefficients & 0.063 & -0.124 & 0.082 & 0.013 \\
\hline
\end{tabular}

\section{The Reverse of Case 6}

Table 13a. The coefficients of variables for the reverse of case 6 .

\begin{tabular}{|c|c|c|c|c|c|c|c|c|c|}
\hline Variables & Constant & $x_{1}$ & $x_{2}$ & $x_{3}$ & $x_{4}$ & $x_{5}$ & $x_{6}$ & $x_{7}$ & $x_{8}$ \\
\hline Coefficients & 1.461 & -0.042 & 0.241 & 0.043 & 0.023 & -0.031 & 0.179 & -0.05 & 0.116 \\
\hline
\end{tabular}

Table 13b. The coefficients of interactions for the reverse of case 6 .

\begin{tabular}{|c|c|c|c|c|}
\hline Interactions & $x_{6} x_{1}$ & $x_{5} x_{2}$ & $x_{8} x_{3}$ & $x_{7} x_{4}$ \\
\hline Coefficients & 0.036 & -0.186 & 0.073 & 0.015 \\
\hline
\end{tabular}

\section{Case 7}

$x_{7}$ is the moderating variable for $x_{1}, x_{8}$ is the moderating variable for $x_{2}, x_{5}$ is the moderating variable for $x_{3}, x_{6}$ is the moderating variable for $x_{4}$.

Table 14a. The coefficients of variables for case 7.

\begin{tabular}{|c|c|c|c|c|c|c|c|c|c|}
\hline Variables & Constant & $x_{1}$ & $x_{2}$ & $x_{3}$ & $x_{4}$ & $x_{5}$ & $x_{6}$ & $x_{7}$ & $x_{8}$ \\
\hline Coefficients & 2.331 & 0.008 & 0.058 & 0.107 & 0.037 & 0.023 & 0.10 & -0.247 & -0.038 \\
\hline
\end{tabular}

Table 14b. The coefficients of interactions for case 7.

\begin{tabular}{|c|c|c|c|c|}
\hline Interactions & $x_{1} x_{7}$ & $x_{2} x_{8}$ & $x_{3} x_{5}$ & $x_{4} x_{6}$ \\
\hline Coefficients & 0.196 & 0.182 & -0.057 & 0.083 \\
\hline
\end{tabular}

\section{The Reverse of Case 7}

Table 15a. The coefficients of variables for the reverse of case 7.

\begin{tabular}{|c|c|c|c|c|c|c|c|c|c|}
\hline Variables & Constant & $x_{1}$ & $x_{2}$ & $x_{3}$ & $x_{4}$ & $x_{5}$ & $x_{6}$ & $x_{7}$ & $x_{8}$ \\
\hline Coefficients & 2.331 & -0.116 & -0.093 & 0.182 & -0.032 & -0.026 & 0.175 & -0.053 & 0.11 \\
\hline
\end{tabular}

Table 15b. The coefficients of interactions for the reverse of case 7.

\begin{tabular}{|c|c|c|c|c|}
\hline Interactions & $x_{7} x_{1}$ & $x_{8} x_{2}$ & $x_{5} x_{3}$ & $x_{6} x_{4}$ \\
\hline Coefficients & 0.119 & 0.176 & -0.077 & 0.075 \\
\hline
\end{tabular}

\section{Case 8}

$x_{8}$ is the moderating variable for $x_{1}, x_{7}$ is the moderating variable for $x_{2}, x_{6}$ is the moderating variable for $x_{3}, x_{5}$ is the moderating variable for $x_{4}$.

Table 16a. The coefficients of variables for case 8.

\begin{tabular}{|c|c|c|c|c|c|c|c|c|c|}
\hline Variables & Constant & $x_{1}$ & $x_{2}$ & $x_{3}$ & $x_{4}$ & $x_{5}$ & $x_{6}$ & $x_{7}$ & $x_{8}$ \\
\hline Coefficients & 1.512 & -0.006 & 0.062 & 0.109 & 0.04 & -0.152 & 0.218 & -0.038 & 0.223 \\
\hline
\end{tabular}


Table 16b. The coefficients of interactions for case 8.

\begin{tabular}{|c|c|c|c|c|}
\hline Interactions & $x_{1} x_{8}$ & $x_{2} x_{7}$ & $x_{3} x_{6}$ & $x_{4} x_{5}$ \\
\hline Coefficients & -0.102 & -0.018 & -0.047 & 0.133 \\
\hline
\end{tabular}

\section{The Reverse of Case 8}

Table 17a. The coefficients of variables for the reverse of case 8.

\begin{tabular}{|c|c|c|c|c|c|c|c|c|c|}
\hline Variables & Constant & $x_{1}$ & $x_{2}$ & $x_{3}$ & $x_{4}$ & $x_{5}$ & $x_{6}$ & $x_{7}$ & $x_{8}$ \\
\hline Coefficients & 1.512 & 0.035 & 0.086 & 0.159 & -0.118 & -0.021 & 0.173 & -0.053 & 0.124 \\
\hline
\end{tabular}

Table 17b. The coefficients of interactions for the reverse of case 8.

\begin{tabular}{|c|c|c|c|c|}
\hline Interactions & $x_{8} x_{1}$ & $x_{7} x_{2}$ & $x_{6} x_{3}$ & $x_{5} x_{4}$ \\
\hline Coefficients & -0.047 & -0.025 & -0.056 & 0.163 \\
\hline
\end{tabular}

Other cases and combinations can be made but the research was limited to 8 cases since the other cases yielded the same result(s).

The moderating effect was 0.01 and was constant in each of hierarchical moderated regression because $\mathrm{R}^{2}$ remains unchanged.

\subsection{Measure of the differences of coefficients of variables and interactions of all the cases and their respective reverses}

In other to measure effectively whether there is a significant differences between the moderation and the reverse moderation, we find the absolute values of the difference between the two. Values closer to zero indicates that the coefficients are not unique and the interactions are commutative while higher values indicate the uniqueness (different) of the coefficients of the independent variables and the interactions are highly non- commutative. Zero value indicates complete non-uniqueness of the predictors and perfect commutativity of the interactions. It can be seen from the results of all the cases that the constants are the same for both the moderation and its reverse, hence, constants were excluded because they easily varnish from the computations. 20 cases were used and the result is on tables 18a and 18b.

Table 18a. The measure of the differences in coefficients of the independent variables between the moderated models and their reversed cases.

\begin{tabular}{|c|c|c|c|c|c|c|c|c|c|}
\hline Model & $x_{1}$ & $x_{2}$ & $x_{3}$ & $x_{4}$ & $x_{5}$ & $x_{6}$ & $x_{7}$ & $x_{8}$ & Mean \\
\hline 1 & 0.082 & 0.159 & 0.003 & 0.119 & 0.125 & 0.029 & 0.001 & 0.03 & 0.065 \\
\hline 2 & 0.002 & 0.007 & 0.038 & 0.045 & 0 & 0.018 & 0 & 0 & 0.014 \\
\hline 3 & 0.130 & 0.030 & 0.004 & 0.020 & 0 & 0 & 0.167 & 0 & 0.044 \\
\hline 4 & 0.002 & 0.141 & 0.010 & 0.074 & 0 & 0 & 0 & 0.033 & 0.033 \\
\hline 5 & 0.133 & 0.021 & 0.001 & 0.084 & 0.190 & 0.016 & 0 & 0.116 & 0.070 \\
\hline 6 & 0.058 & 0.178 & 0.062 & 0.014 & 0.106 & 0.062 & 0.013 & 0.068 & 0.070 \\
\hline 7 & 0.124 & 0.151 & 0.075 & 0.069 & 0.049 & 0.075 & 0.194 & 0.148 & 0.111 \\
\hline 8 & 0.041 & 0.024 & 0.050 & 0.158 & 0.131 & 0.045 & 0.015 & 0.099 & 0.070 \\
\hline 9 & 0.124 & 0.173 & 0.051 & 0.055 & 0.074 & 0.016 & 0 & 0 & 0.062 \\
\hline 10 & 0.123 & 0.169 & 0.026 & 0.005 & 0.075 & 0 & 0.014 & 0 & 0.052 \\
\hline 11 & 0.116 & 0.160 & 0.051 & 0.074 & 0.071 & 0 & 0 & 0.045 & 0.065 \\
\hline 12 & 0.018 & 0.016 & 0.055 & 0.152 & 0.133 & 0.022 & 0 & 0 & 0.050 \\
\hline 13 & 0.018 & 0.007 & 0.011 & 0.027 & 0 & 0.028 & 0.017 & 0 & 0.014 \\
\hline 14 & 0.028 & 0.016 & 0.054 & 0.083 & 0 & 0.043 & 0 & 0.054 & 0.035 \\
\hline 15 & 0.103 & 0.010 & 0.044 & 0.134 & 0.081 & 0 & 0.153 & 0 & 0.066 \\
\hline 16 & 0.130 & 0.032 & 0.047 & 0.049 & 0 & 0.012 & 0.183 & 0 & 0.057 \\
\hline 17 & 0.112 & 0.027 & 0.048 & 0.075 & 0 & 0 & 0.157 & 0.050 & 0.059 \\
\hline 18 & 0.028 & 0.148 & 0.051 & 0.151 & 0.092 & 0 & 0 & 0.079 & 0.069 \\
\hline 19 & 0.037 & 0.153 & 0.054 & 0.053 & 0 & 0.010 & 0 & 0.062 & 0.046 \\
\hline 20 & 0.030 & 0.148 & 0.003 & 0.033 & 0 & 0 & 0.031 & 0.076 & 0.036 \\
\hline mean & 0.072 & 0.089 & 0.037 & 0.074 & 0.056 & 0.019 & 0.047 & 0.043 & 0.055 \\
\hline
\end{tabular}


Table 18b. The measure of the differences in interactions between the moderated models and their reversed cases.

\begin{tabular}{|c|c|c|c|c|c|c|}
\hline Model & Int A & Int B & Int C & Int D & Mean & Overall mean \\
\hline 1 & 0.039 & 0.055 & 0 & 0.022 & 0.029 & 0.053 \\
\hline 2 & 0.001 & 0.002 & 0.007 & 0.012 & 0.006 & 0.011 \\
\hline 3 & 0.081 & 0.010 & 0.001 & 0.003 & 0.024 & 0.037 \\
\hline 4 & 0.009 & 0.006 & 0.002 & 0.026 & 0.011 & 0.025 \\
\hline 5 & 0.063 & 0.157 & 0 & 0.030 & 0.063 & 0.068 \\
\hline 6 & 0.027 & 0.062 & 0.009 & 0.002 & 0.025 & 0.055 \\
\hline
\end{tabular}

Continued Table 18b. The measure of the differences in interactions between the moderated models and their reversed cases. *Int (interaction)

\begin{tabular}{|c|l|l|l|l|l|l|}
\hline 7 & 0.077 & 0.006 & 0.020 & 0.008 & 0.028 & 0.083 \\
\hline 8 & 0.055 & 0.007 & 0.009 & 0.030 & 0.025 & 0.055 \\
\hline 9 & 0.059 & 0.061 & 0.010 & 0.006 & 0.034 & 0.052 \\
\hline 10 & 0.058 & 0.059 & 0.006 & 0.001 & 0.031 & 0.045 \\
\hline 11 & 0.054 & 0.056 & 0.007 & 0.026 & 0.036 & 0.055 \\
\hline 12 & 0.016 & 0.004 & 0.015 & 0.028 & 0.016 & 0.038 \\
\hline 13 & 0.014 & 0.002 & 0.003 & 0.003 & 0.006 & 0.011 \\
\hline 14 & 0.025 & 0.004 & 0.007 & 0.029 & 0.016 & 0.029 \\
\hline 15 & 0.064 & 0.003 & 0.012 & 0.024 & 0.026 & 0.052 \\
\hline 16 & 0.081 & 0.011 & 0.009 & 0.006 & 0.027 & 0.047 \\
\hline 17 & 0.069 & 0.009 & 0.007 & 0.027 & 0.028 & 0.048 \\
\hline 18 & 0.037 & 0.006 & 0.014 & 0.028 & 0.021 & 0.053 \\
\hline 19 & 0.048 & 0.007 & 0.010 & 0.006 & 0.018 & 0.037 \\
\hline 20 & 0.038 & 0.007 & 0.001 & 0.004 & 0.013 & 0.028 \\
\hline Mean & 0.046 & 0.027 & 0.007 & 0.016 & 0.024 & 0.044 \\
\hline
\end{tabular}

\section{Discussion of Results}

The $\mathrm{R}^{2}$ of both the regression and the moderation models were used to compute the interaction effect which is 0.01 , this is possible because $\mathrm{R}^{2}$ remains constant in all the cases and their respective reverses. All the results from the moderation were significantly different from their reverse moderations.

From table 18a, $x_{6}$ is the variable least affected by the reverse moderation while $x_{2}$ is most affected. Also model 2 is the least affected by reverse moderation while model 7 is the most affected by the reverse moderation. Since the mean of both the variables and the models are non-zero, it implies that all the variables and the models are somehow affected by the reverse moderation. From table 18b, on the average, the first terms of the interactions were least affected by the reverse moderation while the third terms of the interactions were most affected by the reverse moderation. Models 2 and 13 are least affected by the reverse moderation while model 5 is most affected by the reverse moderation. Generally, models 2 and 11 are least affected while model 7 is most affected by reverse moderation.

\section{Conclusion}

Moderation is a one-way process; any attempt to interchange the predictors with the moderator variables can alter the moderation results. The moderating effect is small but significant enough to help in distinguishing the 20 models used. The overall average of the measure of the differences in interactions and coefficients of the variables showed the moderation results are unique and reverse interactions are different at varying degrees. The variances are dependent on each model. Hence all the 20 models and the independent variables were affected by reverse moderation, but at varying degrees.

\section{Conflict of Interests}

The authors declare that there is no existence of conflict of interest. 


\section{Acknowledgements}

The authors are grateful to Covenant University for financial support and to the anonymous reviewers for their positive comments towards the improvement of the paper.

\section{References}

Aguinis, H. (2002) Estimation of interaction Effects in Organization Studies. Organizational Research Methods, 5(3): 207-211. Aguinis, H., Beaty, J. C., Boik, R. J. and Pierce, C. A. (2005) Effect size and power in Assessing Moderating Effects of Categorical Variables Using Multiple regression: A 30- Year Review. Journal of Applied Psychology, 90(1): 94-107.

Aguinis, H., Bommer, W. H. and Pierce, C. A. (1996) Improving the estimation of moderating effects by using computer-administered questionnaires. Educational Psychological Measurement, 56(6): 1043-1047.

Aguinis, H. and Gottfredson, R. K. (2010) Best-practice recommendations for estimating interaction effects using moderated multiple regression. Journal of Organizational Behavior 31(6): 776-786.

Aiken, L. S. and West, S. G. (1991) Multiple regression: Testing and interpreting interactions. Sage, Newbury Park, CA.

Anderson, L. E., Stone-Romero, E. F. and Tisak, J. (1996) A Comparison of Bias and Mean Squared Error in Parameter Estimates of Interaction effects: Moderated Multiple Regression versus Error-in-Variable Regression. Multivariate Behavioral Research, 31(1): 69-94.

Arnold, H. J. (1982) Moderator Variables: A classification of conceptual, analytic and Psychometric issues. Organizational Behavior and Human Performance 29(2): 143-174.

Baron, R. M. and D.A. Kenny, D. A. (1986) The moderator-mediator variable distinction in social psychological research: Conceptual, strategic, and statistical considerations. Journal of Personality and Social Psychology, 5(6): 1173-1182.

Bedeian, A. G. and Mossholder, K. W. (1994) Simple questions, not so simple answer: Interpreting interaction terms in moderated multiple regression. Journal of Management 20(1): 159-165.

Bobko, P. and Russell, C. J. (1994) On theory, statistics and the search for interactions in the Organizational Sciences. Journal of Management 20(1): 193-200.

Champoux, J. E. and Peters, W.S. (1987) Form, effect size and power in moderated regression analysis. Educational and Psychological Measurement, 60: 243-255.

Dalal, D. K. and Zickar, M. J. (2012) Some Common Myths About Centering Predictor Variables in Moderated Multiple Regression and Polynomial Regression. Organizational Research Methods 15(3): 339-362.

Dunlap, W. P. and Kemery, E. R. (1987) Failure to Detect Moderating Effects: Is Multicollinearity the Problem? Psychological Bulletin 102(3): 418-420.

Dunlap, W. P. and Kemery, E. R. (1988) Effects of predictor intercorrelations and reliabilities on moderated multiple regression. Organizational Behavior and Human Decision Processes, 41(2): 248-258.

Echambadi, R. and Hess, J. D. (2007) Mean-Centering does not alleviate Collinearity Problems in Moderated Multiple Regression models. Marketing Science 26(3): 438-445.

Evans, Martin G. (1985) A Monte Carlo study of the effects of correlated method variance in moderated multiple regression analysis. Decision Processes, 36(3): 305-323.

Fairchild, A. J. and MacKinnon, D. P. (2009) A General Model for Testing Mediation and Moderation effects. Prevention Science, 10(2): 87-99.

Fisicaro, S. A. and Tisak, J. (1994) A Theoretical Note on the Stochastics of Moderated Multiple Regression. Educational and Psychological Measurement, 54(1): 32-41.

High, W. M. (2005) Rehabilitation for traumatic brain injury. Oxford University Press, Oxford, New York.

Holmbeck, G. N. (1997) Toward terminological, conceptual, and statistical clarity in the study of mediators and moderators: Examples from the child clinical and pediatric psychology literatures. Journal of Consulting and Clinical Psychology 65: 599-610.

Irwin, J.R. and McClelland, G.H. (2001) Misleading Heuristics and moderated multiple regression models. Journal of Marketing Research, 38(1): 100-109.

Jaccard, J., Wan, C. K. and Turrisi, R. (1990) The Detection and Interpretation of interaction effects between Continuous Variables in Multiple Regression. Multivariate Behavioral Research, 25(4): 467-478.

Landis, R. S. and Dunlap, W. P. (2000) Moderated Multiple Regression Tests are Criterion Specific. Organizational Research Methods, 3(3): 254-266.

McClelland, G. H. and Judd, C. M. (1993) Statistical difficulties of detecting interaction and moderator effects. Psychological Bulletin 114(2): 376-390.

Morse, B. J., Johanson, G. A. and Griffeth, R. W. (2012) Using the graded response model to control spurious interactions in moderated multiple regression. Applied Psychological Measurement, 36(2): 122-146.

O'Connor, B. P. (2006) Programs for problems created by continuous variable distributions in moderated multiple regression. Organizational Research Methods, 9(4): 554-567.

Paunonen, S. V. and Jackson, D. N. (1988) Type I error rates for moderated multiple regression analysis. Journal of Applied Psychology, 73(3): 569-573.

Russell, C. J. and Bobko, P. (1992) Moderated regression analysis and Likert Scales: Too Coarse for Comfort. Journal of Applied 
Psychology, 77(3): 336-342.

Saunders, D. R. (1956) Moderator variables in prediction. Educational and Psychological Measurement, 16: 209-222.

Schriesheim, C. A. (1995) Multivariate and moderated within-and between-entity analysis (WABA) using hierarchical linear multiple regression. The Leadership Quarterly, 6(1): 1-18.

Shieh, G. (2010) On the Misconception of Multicollinearity in detection of Moderating effects: Multicollinearity is not always detrimental. Multivariate Behavioral Research 45(3): 483-507.

Shieh, G. (2010) Sample size determination for confidence intervals of interaction effects in moderated multiple regression with continuous predictor and moderator variables. Behavior Research Methods 42(3): 824-835.

Stone, E. F. and Hollenbeck, J. R. (1984) Some issues associated with the use of moderated regression. Organizational Behavior and Human Performance, 34(2): 195-213.

Stone-Romero, E. F. and Anderson, L. E. (1994) Relative Power of Moderated Multiple Regression and the Comparison of Subgroup Correlation Coefficients for Detecting Moderating effects. Journal of Applied Psychology 79(3): 354-359.

Yuan, K. H., Cheng, Y. and Maxwell, S. (2013) Moderation Analysis using a Two-level Regression model. Psychometrika 79(4): 701732.

Zedeck, S. C. (1971) Problems with the use of moderator variables. Psychological Bulletin 76(4): 295-310.

Zedeck, S. C., Cranny, C. J., Vale, C. A. and Smith, P. C. (1971) Comparison of "joint moderators" in three prediction techniques. Journal of Applied Psychology, 55(3): 234-240. 